\title{
Exposure Interruption Duration Unit
}

National Cancer Institute

\section{Source}

National Cancer Institute. Exposure Interruption Duration Unit. NCI Thesaurus. Code C83086.

The unit of measure for the time span of a disruption in the exposure. 